\title{
Megaesophagus in a Patient with Achalasia
}

\author{
João Pinto Flávio Pereira António Banhudo \\ Gastroenterology Department, Amato Lusitano Hospital, Castelo Branco, Portugal
}

\section{Keywords}

Esophageal achalasia · Esophageal motility disorders .

Megaesophagus · Radiography

\section{Megaesófago numa Doente com Acalásia}

\section{Palavras Chave}

Acalásia esofágica · Perturbações motoras do esófago •

Megaesófago · Radiografia

A 84-year-old female with a history of achalasia presented to the emergency department with worsening dysphagia for solids and liquids, regurgitation, and substernal chest pain after meals for the previous $48 \mathrm{~h}$. The real onset of dysphagia had been 40 years before, but due to her resiliency regarding symptoms, the diagnosis of achalasia was established only at 72 years of age. Then, she rejected surgery and thus received 4 treatments with botulinum toxin after an equal number of episodes of food impaction and was medicated with nifedipine. The patient had developed strategies to circumvent dysphagia and maintained a good nutritional status, seeking medical care only in case of complete esophageal obstruction such as in this episode.

\section{KARGER}

E-Mail karger@karger.com www.karger.com/pjg
(C) 2018 Sociedade Portuguesa de Gastrenterologia Published by S. Karger AG, Basel

Karcer

Upen access

This article is licensed under the Creative Commons AttributionNonCommercial-NoDerivatives 4.0 International License (CC BYNC-ND) (http://www.karger.com/Services/OpenAccessLicense). Usage and distribution for commercial purposes as well as any distribution of modified material requires written permission.
On physical examination, she presented good general status, was afebrile and hemodynamically stable with peripheral oxygen saturation of $92 \%$ while breathing ambient air. Thoracic auscultation revealed decreased vesicular breath sounds in the upper right hemithorax. Blood tests were unremarkable except for mild elevation of the inflammatory markers.

A chest radiography revealed an air-fluid level of 13 $\mathrm{cm}$ in diameter, occupying the whole apex of the right hemithorax, actually being the most superior segment of a diffusely enlarged mediastinum (Fig. 1). These findings were consistent with a megaesophagus filled with food in the context of protracted achalasia [1-3]. After 1 week of fasting with parenteral feeding, radiological re-evaluation demonstrated mediastinal radiolucency compatible with complete esophageal voiding (Fig. 2). Upper gastrointestinal endoscopy showed a dilated and tortuous esophageal lumen with colon-like morphology; a small piece of meat was identified adjacent to a puckered gastroesophageal junction (Fig. 3) and removed using a net. With the consent of the patient and aspiring a more durable treatment with disruption of the lower esophageal sphincter [3-5], endoscopic balloon dilation until $30 \mathrm{~mm}$ was performed uneventfully (Fig. 4). After 2 years, the patient still maintains some dietary restrictions but presents a good 


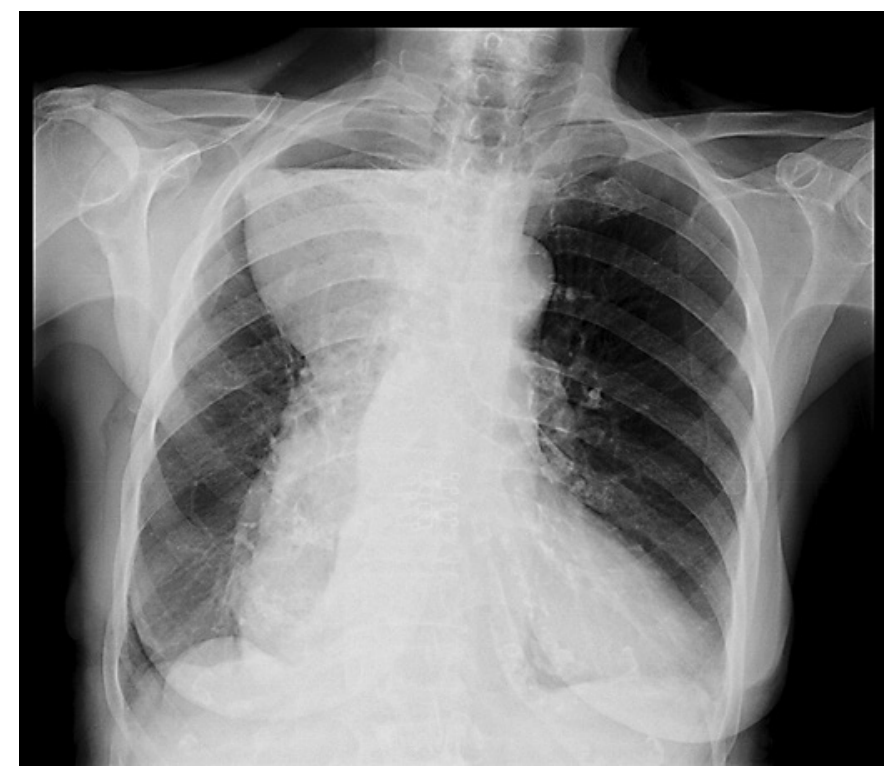

Fig. 1. Chest radiography showing megaesophagus with an airfluid level of $13 \mathrm{~cm}$ in diameter.

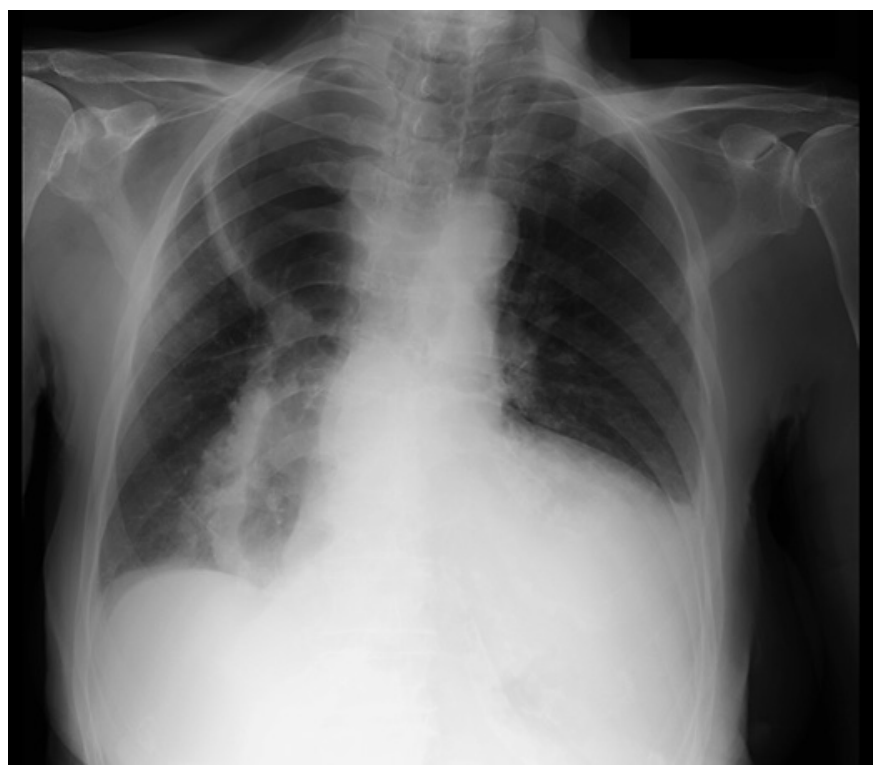

Fig. 2. Chest radiography after 1 week of parenteric nutrition showing mediastinal radiolucency consistent with esophageal voiding.

Fig. 3. Dilated esophageal lumen (left) with a small piece of meat adjacent to a puckered gastroesophageal junction (right).

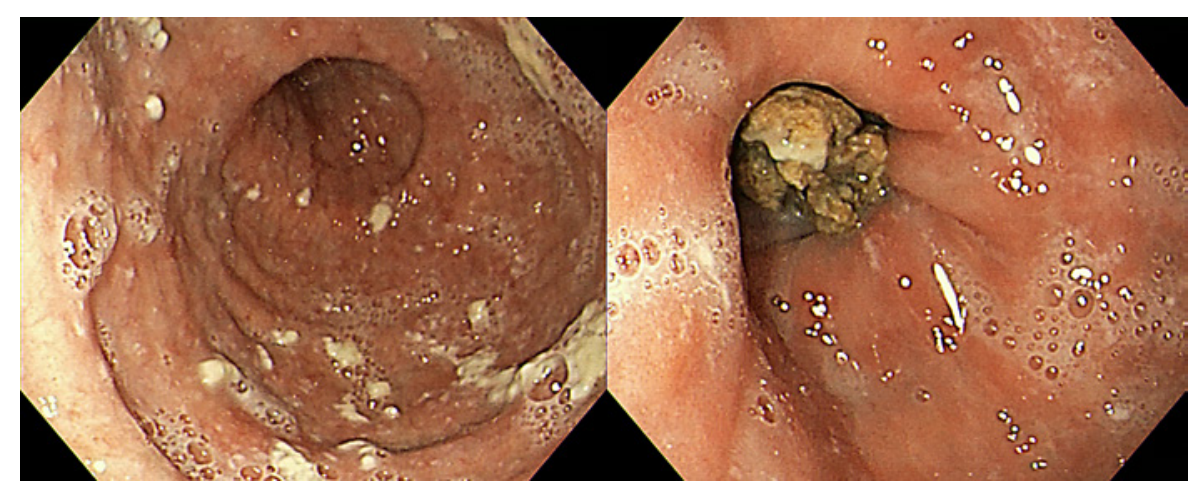

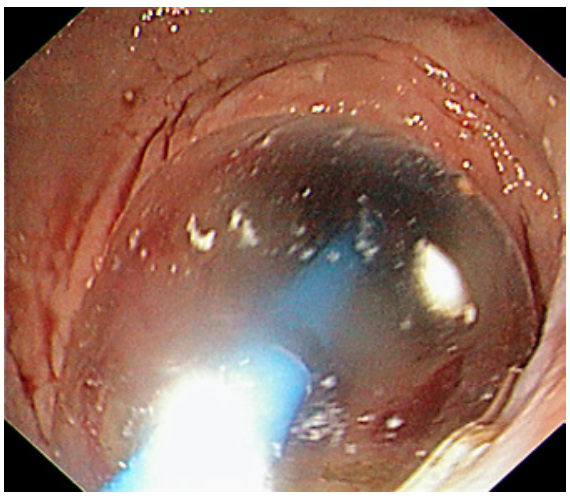

Fig. 4. Pneumatic balloon dilation of the lower esophageal sphincter. nutritional status, has had no episodes of regurgitation, and is generally satisfied with her quality of life.

Achalasia is a primary motility disorder of the esophagus characterized by insufficient relaxation of the lower esophageal sphincter and absence of esophageal peristalsis $[3,5]$. Patients usually present with slowly progressive dysphagia for solids and liquids, regurgitation, weight loss, and occasionally retrosternal chest pain $[2,3]$. The findings of an aperistaltic and dilated esophagus with retained saliva or undigested food and minimal opening of the lower esophageal sphincter or "bird-beak" appearance on endoscopic and radiological studies suggest the diagnosis that is confirmed by esophageal manometry [5]. 
A more definitive treatment requires disrupting the lower esophageal sphincter through endoscopic pneumatic balloon dilation, surgery or per-oral endoscopic myotomy [3-5]. Botulinum toxin injection usually has a temporary effect, being used in patients who are not good candidates for definitive therapies $[3,5]$. Oral pharmacological therapies (e.g., nifedipine) are reserved for patients unfit or unwilling to undergo definitive therapies [5].

In patients with longstanding achalasia left untreated or managed with non-definitive approaches, progressive dilation occurs, producing a megaesophagus morpholo- gy. In such cases, the organ becomes an inert food reservoir and massive food impaction can develop $[1,2]$.

\section{Statement of Ethics}

This study did not require informed consent or review/approval by the appropriate ethics committee.

\section{Disclosure Statement}

The authors have no conflicts of interest to declare.
References

Megaesophagus in a Patient with Achalasia
1 Liang C-Y, Lin M-S: Achalasia. N Engl J Med 2009;360:801.

-2 Okwara C, Cangemi D: Achalasia with megaesophagus. N Engl J Med 2015;373:25.

-3 Stavropoulos S, Friedel D, Modayil R, Parkman H: Diagnosis and management of esophageal achalasia. BMJ 2016;354:i2785.
4 Moonen A, Annese V, Belmans A, et al: Longterm results of the European achalasia trial: a multicentre randomised controlled trial comparing pneumatic dilation versus laparoscopic Heller myotomy. Gut 2016;75:732-739.

5 Vaezi M, Pandolfino J, Vela M: ACG clinical guideline: diagnosis and management of achalasia. Am J Gastroenterol 2013;108: 1238-1249. 